\title{
SOBRE RIMA SONORA Y RIMA SORDA EN CASTELLANO
}

I. Dentro de la estructura rítmica de la estrofa castellana, la reiteración de los timbres articulatorios que llamamos rima, ${ }^{1}$ tiene como función relevar el axis estrófico, o sea dar relieve expresivo al tiempo métrico de cada verso en que coinciden los máximos de intensidad, tono y perceptibilidad. ${ }^{2}$

E1 nicleo rimante castellano ${ }^{3}$ está constituído, en términos generales, por un grupo de fonemas donde alternan, con gran variedad estructural, vocales y consonantes. $\mathrm{Y}$ de la impresibilidad de este nucleo fonemático -alojado siempre en la rama distensiva del sintonema versal-depende en buena parte el vigor comunicativo de la rima en cada verso, y la expresividad de la estrofa en su conjunto rítmico.

2. Las articulaciones vocálicas entran siempre y necesariamente en 1a constitución del nucleo rimante castellano, y son como es sabido siempre también sonoras. ${ }^{4}$ En las articulaciones consonánticas, que normalmente se integran en la rima, puede haber mayor variedad articulatoria, ya que en español es particularmente manifiesta la diferencia entre articulaciones consonantes sonoras y articulaciones consonantes sordas. ${ }^{5} \mathrm{De}$ esta diversidad articulatoria de sonoridad y sordez en las consonantes que integran el nucleo rimante, parecen se pueden derivar capacidades expresivas que trasciendan todo el ámbito estrófico.

1 Cf. RAFAEL DE: BALBfN, Sistema de ritmica castellana. Madrid, 1968, VII, página $\mathrm{I}$.

2 Cf. Idem., VII, 27.

3 Cf. Idem., VII, 2.

- Cf. T. Navarro Tomás, Manual de pronunciación española, Madrid, I932, página 40. A. QUILIS y J. A. FERNÁNDIZ, Curso de fonética y fonología españolas, Madrid, 1964, p. I9.

5 Cf. T. Navarro Tomís, Ob. cit., pp. 72-75 y 143-45. Quilis y Fernández, Ob. cit., pp. I9-2I. 
3. Para verificar la validez de esta hipótesis, he analizado varios poemas de la antología que publicó, en 1908, Marcelino Menéndez y Pelayo con el título de Las cien mejores poesías liricas de la lengua castellana. ${ }^{1}$ Además de la autoridad de su insigne autor, los sesenta años trascurridos desde su publicación aseguran la objetividad en la elección de los textos estudiados ahora, y en su día publicados con propósitos enteramente distintos. Se trata de los veinte sonetos insertos en esta colección y así numerados:
21. Agora, con la aurora se levanta (Luis de León).
23. No me mueve, mi Dios, para quererte (Anónimo).
28. Tu, a quien ofrece el apartado polo (Juan de Arguijo).
29. Yo vi del rojo sol, la luz serena (Juan de Arguijo).
30. Castiga el cielo a Tántalo inhumano (Juan de Arguijo).
3r. En segura pobreza vive Eumelo (Juan de Arguijo).
37. Imagen espantosa de la muerte (Lupercio L. de Argensola).
38. Llevó tras sí los pámpanos octubre (I,upercio I. de Argensola).
39. Dime, Padre común, pues eres justo (Bartolomé $\mathrm{I}_{*}$. de Argensola)
43. Cuelga sangriento de la cama al suelo (Lope de Vega).
47. Suelta mi manso, mayoral extraño (Lope de Vega).
45. ¿Que tengo yo, que mi amistad procuras? (Lope de Vega).
46. Pastor, que con tus silbos amorosos (Lope de Vega).
47. Cuando en mis manos, Rey eterno, os miro (Lope de Vega).
55. Faltar pudo su patria al grande Osuna (Francisco de Quevedo).
56. Ya formidable y espantoso suena (Francisco de Quevedo).
57. Miré los muros de la patria mia (Francisco de Quevedo).
6o. Estas que fueron pompa y alegria (P. Calderón de la Barca).
7I. Hermosa fuente que al vecino rio (José Joaquín de Mora).
Ioo. Ya de mi amor la confesión sincera (Manuel del Palacio).

4. Me ha parecido que pueden prestar base suficiente a este primer análisis proyectado, poemas que forman la quinta parte de los elegidos por Menéndez y Pelayo, máxime teniendo en cuenta que son obras escritas en tres siglos distintos, XVI, XVII y XIX; y recogen en su temática desde motivos religiosos (números 23, 39, 43, 45, 46 y 47); filosóficos y morales (números 29, 30, 3I, 37, 38, 56, 57 y 60); y amorosos (números 2I, 44 y IOO); hasta temas históricos y descriptivos (números 28, 55 y 7I).

La variedad secular -en el tiempo- y la diversidad temática son garantía de que la expresividad de las veinte composiciones puede ofrecer amplia gama vivencial. $\mathrm{Y}$ por si ello fuera poco, la personalidad humana y poética de Fray Luis de León y de Manuel del Palacio, de Juan de Arguijo y los Argensola, de Lope y José Joaquín de Mora, de Calde-

1 Sexta edición revisada por Mrguer, ARTIGaS, Madrid, I967. 
rón y Quevedo, parece prevenir contra cualquier achaque de uniformidad y monotonía.

5. En cuanto a la elección de la estrofa analizada, me incliné por el soneto porque su desarrollo versal de estrofa compuesta ${ }^{1}$ permite variación grande en las combinaciones de la rima, que articula como mínimo cuatro nucleos rimantes distintos. Tiene, además, en su estructura hasta finales del siglo XIX, gran estabilidad en su contrucción rítmica, y por su factura estilística, es paradigma estrófico reflexivo y cuidado, capaz de intensa matización y finura expresiva.

\section{II}

6. Designaré conı rima sonora, el nucleo rimante compuesto exclusivamente de articulaciones sonoras, ya sean vocálicas o consonánticas, llamaré rima sorda, al nucleo que incluye articulaciones sordas. Siendo el factor diferencial de estos tipos de rima, la diversidad articulatoria de las consonantes que se localizan en la rama distensiva del grupo melódico versal, pudiera pensarse que la proporción entre rima sonora y rima sorda podría ser la misma que se registra en general entre articulaciones consonánticas sonoras y articulaciones consonánticas sordas, en la masa fonemática del idioma castellano. ${ }^{2} \mathrm{O}$ sea que la rima sonora represente el sesenta por ciento $(60 \%)$ de los nucleos rimantes configurados, mientras que la rima sorda constituya el restante cuarenta por ciento (40\%).

Sin embargo, estos porcentajes, válidos para la prosa y la lengua coloquial, solo en parte se reflejan en el uso de la rima configurada en los veinte sonetos. E1 total de doscientos ochenta versos (280) que se integran en las composiciones analizadas, tienen en conjunto ciento sesenta y seis rimas sonoras $(60 \%)$, por ciento catorce rimas sordas $(40 \%)$. Pero al estudiar por separado cada uno de los sonetos elegidos, se manifiestan en la construcción de la rima siete tipos distintos, originados en la personal iniciativa de los autores:

1 Cf. BALBín, Ritmica, VIII, 26.

2 Cf. Tomás Navarro, Fonología española, Syracuse, New York, 1946, páginas 29-30. 
7. Estos tipos diversificados por la variante proporción de rima sonora y rima sorda ${ }^{1}$ son:

Tipo A Con catorce rimas o nucleos rimantes sonoros (Ioo por roo de sonoridad) Aparece en:

43. Iope de Vega (Cuelga sangriento de la cama al suelo).

44. Lope de Vega (Suelta mi manso, mayoral extraño).

56. Francisco de Quevedo (Ya formidable y espantoso suena).

6o. P. Calderón de la Barca (Estas que fueron pompa y alegría).

Tipo $B$ Diez rimas sonoras y cuatro rimas sordas (70 por roo de sonoridad/30 por Ioo de sordez).

21. Iuis de León (Agora, con la aurora se levanta).

23. Anónimo (No me mueve, mi Dios, para quererte).

29. Juan de Arguijo (Yo vi del rojo sol, la luz serena).

3I. Juan de Arguijo (En segura pobreza vive Eumelo).

38. Lupercio L. de Atgensola (Llevó tras si los pámpanos octubre).

45. Lope de Vega (¿Qué tengo yo, que mi amistad procuras?).

55. Francisco de Quevedo (Faltar pudo su patria al grande Osuna)

Tipo $C$ Ocho rimas sonoras y seis rimas sordas (6o por roo de sonoridad/40 por roo de sordez).

3o. Juan de Arguijo (Castiga el cielo a Tántalo inhumano).

7x. José J. de Mora (Hermosa fuente que al vecino rio).

Tipo $D$ Seis rimas sonoras y ocho rimas sordas (40 por Ioo de sonoridad/6o por roo de sordez).

57. Francisco de Quevedo (Miré los muros de la patria mía).

Tipo E Cuatro rimas sonoras y diez rimas sordas (30 por roo de sonoridad/70 por Ioo de sordez).

1 Ia presencia de consonantes fricativas alveolares y prepalatales en los nucleos rimantes analizados, no es obstáculo para la validez de los porcentajes establecidos más abajo. En primer lugar porque la publicación de los sonetos que incluyen consonantes ensordecidas, data del siglo XVII, época en que con toda probabilidad se había consumado el ensordecimiento. $\mathrm{Y}$ además porque las rimas en todo caso cuestionables, no constituyen más del I6 por roo de los núcleos estudiados. Cf. DÁmAso ALONSO, "La fragmentación fonética peninsular», en Enciclopedia Lingïistica Hispánica, Madrid, 1962, Suplemento del t. I, pp. 85-IOo; RAFAEI. LAPESA, Historia de la lengua española, Madrid, i965, pp. 245-48; RAFAEL DF BALBfN y ANTONIO RoLDÁ, Estudio preliminar a la Gramática de la lengua vulgar de España (Lovaina, 1959), Madrid, I966, pp. XXXVI-XL. 
28. Juan de Arguijo (Tu, a quien ofrece el apartado polo).

46. Lope de Vega (Pastor, que con tus silbos amorosos).

47. Lope de Vega (Cuando en mis manos, Rey eterno, os miro).

10o. Manuel del Palacio ( $Y a$ de mi amor la confesión sincera).

Tipo $F$ Dos rimas sonoras y diez rimas sordas (I5 por roo de sonoridad/85 por Ioo de sordez).

39. Bartolomé $\mathrm{L}$. de Argensola (Dime, Padre común, pues eres justo).

Tipo $G$ Catorce vimas sordas (roo por roo de sordez).

37. Lupercio L. de Argensola (Imagen espantosa de la muevte).

8. La libertad configuradora de cada uno de los poetas en la construcción del soneto da como resultado notas propias y personales en cada autor, que se traducen con porcentajes distintos para el uso de la rima y son tal vez rasgos linguiísticos peculiares de cada estilo.

Se registra predominio de rimas sonoras en esta proporción.

\begin{tabular}{|c|c|}
\hline Fray Iuis de León............. & 70 \\
\hline Anónimo................ & 70 \\
\hline 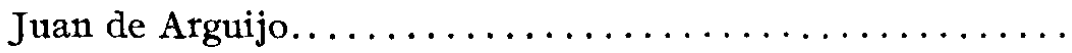 & 57 \\
\hline Lope de Vega............ & 66 \\
\hline Francisco de Quevedo........ & 72 \\
\hline edro Calderón de la Barca......... & 100 \\
\hline José J. de Mora & 60 \\
\hline
\end{tabular}

Tienen predominio de rimas sordas, sobre las rimas sonoras:

Manuel del Palacio.......................... $30 \quad 70$

9. El material rítmico analizado - y con estricta referencia a élcreo que permite anotar algunas observaciones:

a) La cronología de los sonetos estudiados no explica sus diferencias en la construcción de la rima. Así tienen un 60 por Ioo de rimas sonoras por un 40 por Ioo de rimas sordas, el soneto número 30 (Castiga el cielo a Tántalo inhumano) de J. de Arguijo, datado en el siglo xvir; y el núm. 7I (Hermosa fuente que al vecino rio) de J. J. de Mora, compuesto en el siglo $\mathrm{xIx}$. $\mathrm{Y}$ en cambio el poema número 37 (Imagen espantosa de la muerte) de L. L. de Argensola, construído con un Ioo por Ioo de 
rimas sordas, es contemporáneo de los sonetos número 43 (Cuelga sangriento de la cama al suelo) y número 44 (Suelta mi manso, mayoral extraño), ambos de Lope de Vega y configurados con un Ioo por Ioo de rimas sonoras.

b) Tampoco el tema de las composiciones parece explicar sus diferencias de estructura. En los grupos que más arriba quedan enumerados, el tipo $B$-configurado con 70 por roo de sonoridad y 30 por roo de sordez- incluye sonetos, amorosos de Fray Luis de León (número 2I); filosóficos, de J. de Arguijo (números 29 y 3I) y de L. L. de Argensola (número 38); históricos, de F. de Quevedo (número 55); y de temática religiosa, originales de un Anónimo (núm. 28), y de Lope de Vega (número 45 ).

d) Sin que pueda tenerse por concluyente y decisivo, el nivel de la creación poética en cada autor podría dar indicio orientador acerca de la compleja variedad con que se construye rima sonora y rima sorda. La proporción media de 60 por Ioo de sonoras por 40 por Ioo de sordas, sólo se registra en la pluma de dos poetas (J. de Arguijo y J. J. de Mora), hábiles y elegantes en la construcción rítmica, pero menores en el logro poético, La configuración del soneto con Ioo por Ioo de rimas sonoras se encuentra por contraste en tres poetas mayores, como lo son Lope de Vega, Quevedo y Calderón de la Barca.

e) Pero seguramente donde está la clave cierta de la personal diversidad con que se emplean las rimas, es el fondo oscuro, pero firme y certero de los hábitos lingüísticos contraídos por cada uno de los poetas escogidos en Menéndez y Pelayo, y estudiados aquí. La proporción media (6o por roo sonoridad/40 por roo sordez) aparece con J. de Arguijo y con J. J. de Mora que son, entre los autores analizados, los dos únicos andaluces.

Lope de Vega, Quevedo y Calderón, que construyen con predominio de sonoridad y llegan al empleo del roo por roo de rimas sonoras, son los tres madrileños y oriundos de la Montaña.

$\mathrm{Y}$ los tres autores que, entre los seleccionados, construyen el soneto con predominio de rimas sordas, adquirieron su lengua en areas geográficas aragonesas o limítrofes de Aragón. Los dos Argensola se forman en Barbastro y en Huesca, y el poeta Manuel del Palacio nace, y vive su infancia, en Lérida.

f) La diferencia de sonoridad y sordez en la articulación de las consonantes castellanas, es factor de matización expresiva al integrarse las articulaciones consonánticas en el nucleo rimante de los versos que constituyen la estrofa.

RAFAEL DE BALBÍN 